\title{
Adsorption of Rose Bengal Dye from Aqueous Solution onto Zinc Chloride Activated Carbon
}

\author{
V Nandhakumar ${ }^{1 *}$, A Rajathi ${ }^{1}$, R Venkatachalam ${ }^{1}$, K Ramesh $^{2}$ and S Savithiri ${ }^{3}$ \\ ${ }^{1}$ Department of Chemistry, AVVM Sri Pushpam College, Poondi, India \\ ${ }^{2}$ Department of Chemistry, Arasu Engineering College, Kumbakonam, India \\ ${ }^{3}$ Department of Chemistry, Manakula Vinayagar Engineering College, Puducherry, India
}

Received: July 10, 2015; Accepted: July 29, 2015; Published: August 10, 2015

*Corresponding author: V Nandhakumar, Associate professor of Chemistry, A.V.V.M Sri Pushpam College, Poondi, Tamil Nadu, S. India - 613006,

Tel:+91 9894439942; E- mail: vnchem14@gmail.com; vnandhakumar12@yahoo.com

\begin{abstract}
A low cost activated carbon was prepared from fruit shell of Terminalia catappa Linn (Indian almond), waste plant residues and evaluated its adsorbing behaviour of Rose Bengal (RB) dye from aqueous solution by batch mode adsorption experiments. The activated carbon was prepared using zinc chloride as activating agent. This study examined the effect of contact time, adsorbent dosage, initial dye concentration, $\mathrm{pH}$, other ions and temperature. Equilibrium data were obtained at $303,313,323,333$ and $343 \mathrm{~K}$ temperatures for the initial dye concentrations of $10,20,30,40$ and $50 \mathrm{mg} / \mathrm{L}$. Maximum dye removal capacity was observed at $\mathrm{pH}$ 6. Experimental data obtained were fitted into Lagergren, Ho and Weber Morris kinetic models for pseudo first-order, pseudo secondorder and intra-particle diffusion kinetic study. The adsorption kinetic was found to follow pseudo second-order kinetic model as per the statistical tool 'Sum of Squared Error' (SSE) result. The equilibrium adsorption data were analysed by Langmuir, Freundlich, Temkin and Dubinin-Radushkevich and isotherms. Thermodynamic parameters; Gibb's free energy $\left(\Delta \mathrm{G}^{0}\right)$, Enthalpy $\left(\Delta \mathrm{H}^{0}\right)$ and Entropy $\left(\Delta \mathrm{S}^{0}\right)$ of the adsorption process were also evaluated. Analysis of these values inferred that the adsorption was endothermic, spontaneous and proceeded with increased randomness.
\end{abstract}

Keywords: Adsorption; Rose Bengal dye; $\mathrm{ZnCl}_{2}$ Activated Carbon; Kinetics; Isotherms; Thermodynamic Parameters

\section{Introduction}

Now a day's synthetic dyes have been widely used in many industrial processes especially in the textile industry. The varieties of dyes include; acidic, reactive, basic, disperse, azo, diazo, anthraquinone based and metal complex. These dyes have a complex structure and low biodegradability [1]. These dyestuffs cause huge threat to the environment. Rose Bengal (RB) dye is harmful and can cause severe toxic effects on the human corneal epithelium. The dye is extremely hazardous when it comes in contact with skin and creates irritation, itching, scaling, reddening and even blistering. It also causes inflammation, redness, watering and itching in the eyes. On ingestion by inhalation it damages mucous membranes, which leads to respiratory irritation in humans. Numerous efforts and research have been made to remove these dangerous chemical compounds, there are many traditional techniques applied in the removal process such as coagulation, flocculation, activated carbon adsorption, membrane filtration, photo degradation and sedimentation. Among these methods, adsorption is proved to be superior to other techniques. Adsorption using activated carbon gave fruitful results for the removal of dye from wastewater. The extent of dye removal depends upon the kind of dye, nature of adsorbent and experimental conditions. Preparation of activated carbon from waste plant bio masses and evaluating its adsorbing potential is the recent trend of research. Fruit shell of Terminalia catappa Linn is a waste plant bio mass which is chosen as precursor for the preparation of activated carbon in this present investigation [2] and the Zinc chloride activation method is adopted as it has the advantage of producing excellent pores as reported in earlier literatures [3].

\section{Materials and Methods}

\section{Preparation of adsorbate}

Rose Bengal, all so known as Acid Red 94 [Molecular formula $\mathrm{C}_{20} \mathrm{H}_{4} \mathrm{Cl}_{4} \mathrm{I}_{4} \mathrm{O}_{5}$ ] [IUPAC Name: 4,5,6,7-Tetra chloro - 3',6'dihydroxy-2', 4', 5', $7^{\prime}$-tetraiodo - $3 H$ - Spiro [isobenzofuran-1,9'xanthen]-3-one]. Maximum wavelength $\left(\lambda_{\max }\right)$ for the absorption of this dye is $530 \mathrm{~nm}$. Stock solution of $1000 \mathrm{mg} / \mathrm{L}$ was prepared by dissolving $1 \mathrm{~g}$ of dye in $1000 \mathrm{~mL}$ of double distilled water. Required experimental solutions say 10, 20, 30, 40 and $50 \mathrm{mg} / \mathrm{L}$ were prepared from the stock solution by proper dilution.

\section{Preparation of adsorbents}

The Terminalia catappa Linn fruit shells were collected from A.V.V.M. Sri Pushpam College campus, Thanjavur District., washed with distilled water to remove the surface adhered particles, dried in sun light for 4 days, chopped into small pieces and powdered in a pulveriser. $50 \mathrm{~g}$ of the powder was mixed with $100 \mathrm{~mL}$ of $60 \% \mathrm{ZnCl}_{2}$ solution. The slurry was kept at room temperature for 24 hours, to ensure the complete access of the $\mathrm{ZnCl}_{2}$ to the T. Catappa shell powder. Excess of solution was decanted and the slurry was heated in muffle furnaces at $723 \mathrm{~K}$ 
for 3 hours. Thus the carbonized samples were washed with $0.5 \mathrm{M}$ $\mathrm{HCl}$ followed with distilled water until the $\mathrm{pH}$ of the washings attain 7.0. Then it was dried in a hot air oven at $383 \mathrm{~K}$ for 1 hour. The dried material was ground and sieved to get particle size in between $73 \mu \mathrm{m}$ and $150 \mu \mathrm{m}$. It was designated as T. catappa Zinc Chloride Activated Carbon (TCZAC).

\section{Adsorption experiments}

Batch experiments were conducted. The experiments were carried out in an orbital shaker at a constant speed of $130 \mathrm{rpm}$ using $250 \mathrm{~mL}$ conical flasks containing predetermined dose of TCZAC with $50 \mathrm{~mL}$ of dye solution. After agitating, the samples were drawn from the flasks and the adsorbents were separated from the solution by centrifugation at $1000 \mathrm{rpm}$ for $10 \mathrm{~min}$. The absorbance of the of the supernatant solution was determined spectrophotometrically at $\lambda_{\max } 530 \mathrm{~nm}$ using Systronics 2202 make UV-Visible spectrophotometer to estimate the residual dye concentration. Percentage of removal and the quantity of adsorbate adsorbed were calculated using the following equations.

$$
\begin{aligned}
& \mathrm{q}_{\mathrm{t}}=\left(\mathrm{C}_{\mathrm{i}}-\mathrm{C}_{\mathrm{t}}\right) \frac{\mathrm{V}}{\mathrm{W}} \\
& \% \text { of Removal }=\left(\mathrm{C}_{\mathrm{i}}-\mathrm{C}_{\mathrm{t}}\right) / \mathrm{C}_{\mathrm{i}} \times 100
\end{aligned}
$$

Where;

$\mathrm{C}_{\mathrm{i}}$ and $\mathrm{C}_{\mathrm{t}}$ are the concentration of adsorbate $(\mathrm{mg} / \mathrm{L})$ at initial stage and at time't' respectively

$\mathrm{V}$ is the volume of solution (L)

$\mathrm{W}$ is the mass of adsorbent $(\mathrm{g})$.

Experimental results obtained from the effect of initial concentration and contact times were employed in testing the applicability of isotherm and kinetic models.

\section{Effect of solution $\mathrm{pH}$}

Solution $\mathrm{pH}$ is an important factor which influences the transfer of adsorbate from aqueous solution to adsorbent by altering the speciation of the adsorbate as well as the surface charges of adsorbent. To study the effect of $\mathrm{pH}$ on adsorption, $50 \mathrm{mg}$ of TCZAC was added to $50 \mathrm{~mL}$ of $20 \mathrm{mg} / \mathrm{L}$ of the RB dye solution of the different $\mathrm{pH}$. Initial $\mathrm{pH}$ of the solution was maintained by adding $0.1 \mathrm{M} \mathrm{HCl}$ or $0.1 \mathrm{NaOH}$.

\section{Effect of adsorbent dosage}

The effect of dose was studied by taking adsorbents from 10 to $100 \mathrm{mg} / 50 \mathrm{~mL}$ for $20 \mathrm{mg} / \mathrm{L}$ of the RB dye solution.

\section{Effect of contact time and initial concentration}

Effect of initial concentration was studied by taking 10 , $20,30,40$ and $50 \mathrm{mg} / \mathrm{L}$ of RB dye solutions. The \% of removal was determined at regular time intervals up to 160 minutes of agitation time.

\section{Kinetic Studies}

Kinetic studies are necessary to determine the different operation conditions for the sorption of dye. The kinetics of RB onto TCZAC was analysed using pseudo-first order, pseudosecond order and intra particle diffusion kinetic models as below.

\section{Pseudo - first-order kinetic model}

The linearised form of the pseudo-first order equation of Lagergren is [4]

$$
\log \left(\mathrm{q}_{\mathrm{e}}-\mathrm{q}_{\mathrm{t}}\right)=\log \mathrm{q}_{\mathrm{e}}-\mathrm{k}_{1} / 2.303 \times \mathrm{t}
$$

Where;

$\mathrm{q}_{\mathrm{e}}$ and $\mathrm{q}_{\mathrm{t}}$ are the adsorption capacity at equilibrium and at time $\mathrm{t}$ respectively $(\mathrm{mg} / \mathrm{g}) . \mathrm{k}_{1}$ is the rate constant of pseudo first-order adsorption. From the plot drawn between $\log \left(\mathrm{q}_{\mathrm{e}}-\mathrm{q}_{\mathrm{t}}\right)$ and $t$, values of $\mathrm{k}_{1}$ and $\mathrm{q}_{\mathrm{e}}$ can be calculated from the slopes and intercepts of the plot respectively.

\section{The second-order kinetic model}

The pseudo-second order kinetic model (Ho equation) is represented by the following linear equation [5].

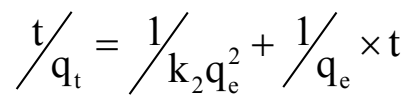

Where; $\mathrm{q}_{\mathrm{e}}$ and $\mathrm{q}_{\mathrm{t}}$ are the adsorption capacity at equilibrium and at time $t$ respectively $(\mathrm{mg} / \mathrm{g})$.

The initial adsorption rate, $\mathrm{h}(\mathrm{mg} /(\mathrm{g} \min ))$,

$$
\mathrm{h}=\mathrm{k}_{2} \mathrm{q}_{\mathrm{e}}^{2}
$$

The Plot drawn between of $t / q_{t}$ and $t$ gave a straight line, from which 'calculated adsorption capacity $\mathrm{q}_{\mathrm{e}(\mathrm{cal})} \mathrm{mg} / \mathrm{g}$, and the second-order rate constants $\mathrm{k}_{2}$ (g/ (mg min)) can be determined from the slopes and intercepts of plots respectively.

\section{Intra-particle diffusion study}

The mechanism of adsorption of a sorbate on a sorbent follows a series of steps. The slowest of these steps control the overall rate of the process. Generally, pore and intra particle diffusion are often rate limiting in a batch reactor while for a continuous flow system, film diffusion is the rate limiting step [6]. Previous studies [7-9] by various researchers showed that the plot of $q_{t}$ versus $t^{1 / 2}$ represents multi linearity which characterizes two or more steps involved in the sorption of sorbate by a sorbent. These involve transport of the solute molecules from the aqueous phase to the surface of the solid particulates and diffusion of the solute molecules into the interior of the pores, which is usually a slow process.

The effect of contact time experimental results can be used to study the rate limiting step in the adsorption process, as shown by Weber and Morris [10]. Since the particles are vigorously agitated during the adsorption period, it is probably reasonable to assume that the rate is not limited by mass transfer from the bulk solution to the particle external surface; one might then postulate that the rate limiting step may be either film diffusion or intraparticle diffusion. As they act in series, the slower of the two will be the rate determining step. According to Weber and Morris, an intra-particle diffusion Co-efficient $\mathrm{k}_{\mathrm{p}}$ is defined by the equation: 


$$
\mathrm{q}_{\mathrm{t}}=\mathrm{k}_{\mathrm{p}} \mathrm{t}^{1 / 2}+\mathrm{C}
$$

Weber and Morris plot was drawn between $\mathrm{q}_{\mathrm{t}}$ and $\mathrm{t}^{1 / 2}$ gave a straight line. Where $\mathrm{k}_{\mathrm{p}}\left(\mathrm{mg} / \mathrm{g} / \min ^{0.5}\right)$ is the intra particle diffusion rate constant and $\mathrm{C}$ is the thickness of the boundary film [11]. The $\mathrm{k}_{\mathrm{p}}$ and $\mathrm{C}$ values obtained from the slopes and intercepts.

\section{Effect of temperature studies}

The adsorption study was carried out at different temperatures $(303,313,323,333$, and $343 \mathrm{~K})$ for the RB solutions initial concentration of between $10 \mathrm{mg} / \mathrm{L}, 20 \mathrm{mg} / \mathrm{L}, 30 \mathrm{mg} / \mathrm{L}$, $40 \mathrm{mg} / \mathrm{L}$ and $50 \mathrm{mg} / \mathrm{L}$, with the stirring for a period of $160 \mathrm{~min}$.

\section{Isotherm studies}

It is important to fit the equilibrium data in different isotherm equations to give useful information of the adsorption process for the conception of the four isotherm models of adsorption were used in this study namely Langmuir, Freundlich, Temkin and Dubinin-Radushkevich.

\section{Langmuir isotherm}

The linear form of Langmuir isotherm equation is often written in as [12]

$$
\mathrm{C}_{\mathrm{e}} / \mathrm{q}_{\mathrm{e}}=1 / \mathrm{q}_{\mathrm{m}} \mathrm{b}+\mathrm{C}_{\mathrm{e}} / \mathrm{q}_{\mathrm{m}}
$$

where $q_{e}$ is the amount of solute adsorbed per unit mass of adsorbent (mg/ g), $\mathrm{C}_{\mathrm{e}}$ the equilibrium concentration of solute in the bulk solution $(\mathrm{mg} / \mathrm{L}), \mathrm{q}_{\mathrm{m}}$ is the maximum monolayer adsorption capacity or saturation capacity $(\mathrm{mg} / \mathrm{g}$ ) and b is the adsorption energy, $b$ is the reciprocal of the concentration at which half saturation of the adsorbent is reached. Values of ' $\mathrm{q}_{\mathrm{m}}$ ' and ' $b$ ' can be calculated from the slopes and intercepts of the graph is drawn between $\mathrm{C}_{e} / \mathrm{q}_{e}$ and $\mathrm{C}_{\mathrm{e}}$.

The essential characteristics of Langmuir isotherm can be described by a separation factor, $\mathrm{R}_{\mathrm{L}}$, which is defined by the following equation

$$
\mathrm{R}_{\mathrm{L}}=1 /\left(1+\mathrm{bC}_{0}\right)
$$

Where;

$\mathrm{C}_{0}$ is the initial concentration of the adsorbate solution. The separation factor $\mathrm{R}_{\mathrm{L}}$ indicates the shape of the isotherm and the nature of the adsorption process as given below:

\begin{tabular}{|l|l|}
\hline$R_{L}$ value & Nature of the process \\
\hline$R_{L}>1$ & Unfavourable \\
\hline$R_{L}=1$ & Linear \\
\hline $0<R_{L}<1$ & Favourable \\
\hline$R_{L}=0$ & Irreversible \\
\hline
\end{tabular}

\section{Freundlich isotherm}

The liner form of Freundlich isotherm model is represented by [13]

$$
\ln \mathrm{q}_{\mathrm{e}}=\ln \mathrm{k}_{\mathrm{f}}+(1 / \mathrm{n}) \ln \mathrm{C}_{\mathrm{e}}
$$

Where; $q_{e}$ is the amount of adsorbate adsorbed (mg/g), $C_{e}$ is the equilibrium concentration of dye solution $(\mathrm{mg} / \mathrm{L})$ and $\mathrm{k}_{\mathrm{f}}$ and $\mathrm{n}$ are the constants incorporating all factors affecting the adsorption capacity and intensity of adsorption, respectively. Values of ' $n$ ' and ' $k$ ' were determined from slopes and intercepts of the graph drawn between the $\ln C_{e}$ and $\ln q_{e}$.

\section{Temkin isotherm}

The Temkin isotherm assumes that the heat of sorption in the layer would decrease linearly with coverage due to sorbate sorbent interactions. Further the fall in the heat of adsorption is not logarithmic as stated in Freundlich expression. Linear form of Temkin isotherm equation is [14].

$$
\mathrm{q}_{\mathrm{e}}=\mathrm{RT} / \mathrm{b}_{\mathrm{T}} \ln \mathrm{a}_{\mathrm{T}}+\mathrm{RT} / \mathrm{b}_{\mathrm{T}} \ln \mathrm{C}_{\mathrm{e}}
$$

Where,

$\mathrm{b}_{\mathrm{T}}$ is the Temkin constant related to the heat of sorption (J/ $\mathrm{mg}$ ) and $\mathrm{a}_{\mathrm{T}}$ the equilibrium binding constant corresponding to the maximum binding energy $\left(\mathrm{L} / \mathrm{g}\right.$ ) The Temkin constants $\mathrm{a}_{\mathrm{T}}$ and $\mathrm{b}_{\mathrm{T}}$ were calculated from the slopes and intercepts of graph drawn between $\mathrm{q}_{\mathrm{e}}$ versus $\ln \mathrm{C}_{\mathrm{e}}$.

\section{Dubinin - Radushkevich isotherm}

The Linear form of Dubinin-Radushkevich isotherm is [15].

$$
\ln \mathrm{q}_{\mathrm{e}}=\ln \mathrm{q}_{\mathrm{D}}-\mathrm{B} \varepsilon^{2}
$$

Where,

$\mathrm{q}_{\mathrm{D}}$ is the theoretical saturation capacity ( $\mathrm{mg} / \mathrm{g}$ ) B is a constant related to the mean free energy of adsorption per mole of the adsorbate $\left(\mathrm{mol}^{2} / \mathrm{J}^{2}\right)$ and $\varepsilon$ is Polanyi potential which is related to the equilibrium concentration as follows.

$$
\varepsilon=\mathrm{RT} \ln \left(1+1 / \mathrm{C}_{\mathrm{e}}\right)
$$

A plot of $\ln q_{e}$ vs. $\varepsilon^{2}$ gives a linear line and the constants $q_{D}$ and $\mathrm{B}$ calculated from the slopes and intercepts respectively. The mean free energy of adsorption $E$ was calculated from B using the following equation

$$
\mathrm{E}=1 /(2 \mathrm{~B})^{1 / 2}
$$

From this mean free energy of activation we can predict whether an adsorption is physisorption or chemisorption. If this energy is lesser than $8 \mathrm{~kJ} / \mathrm{mol}$, the adsorption is physisorption and if the energy is more than $8 \mathrm{~kJ} / \mathrm{mol}$, the adsorption is chemisorption.

\section{Adsorption thermodynamics}

Thermodynamic parameters such as change in free energy $\Delta \mathrm{G}^{\circ}(\mathrm{kJ} / \mathrm{mol})$, enthalpy $\Delta \mathrm{H}^{\circ}(\mathrm{kJ} / \mathrm{mol})$ and entropy $\left.\Delta \mathrm{S}^{\circ} \mathrm{J} / \mathrm{K} / \mathrm{mol}\right)$ were determined using the following equations.

$$
\mathrm{k}_{\mathrm{d}}=\mathrm{C}_{\text {solid }} / \mathrm{C}_{\text {liquid }}
$$


<smiles>COc1c(I)cc2c(-c3c(Cl)c(Cl)c(Cl)c(Cl)c3C(=O)O[Na])c3cc(I)c(=O)c(I)c-3oc2c1I</smiles>

Figure 1: Structure of Rose Bengal dye.

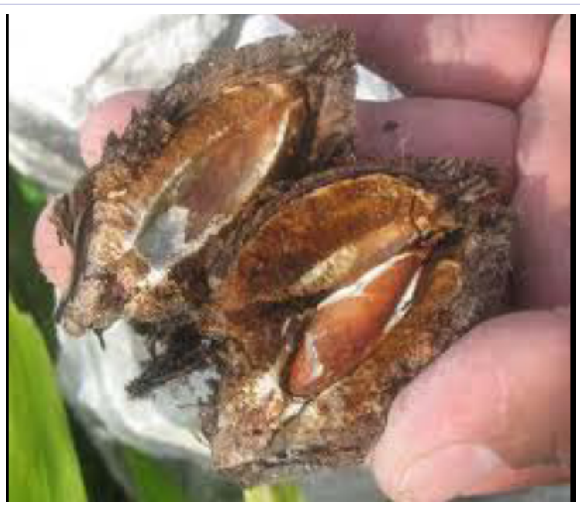

Figure 2: Terminalia catappa fruit shell.

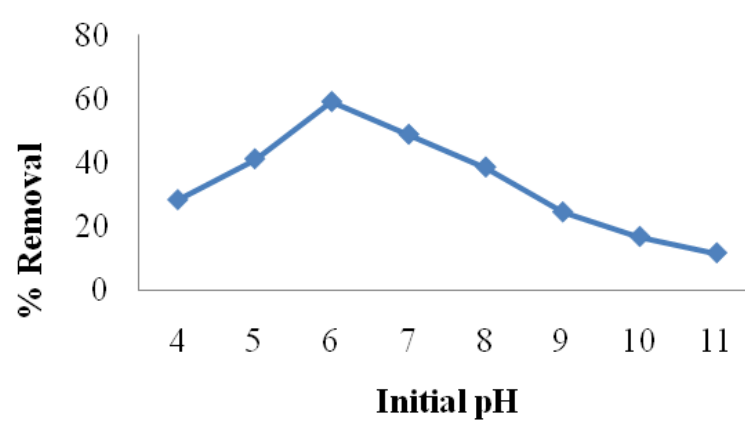

Figure 3: Effect of $\mathrm{pH}$ on the adsorption of RB dye. [RB]: $20 \mathrm{mg} / \mathrm{L}$; Dose: $50 \mathrm{mg} / 50 \mathrm{ml}$; contact time: $160 \mathrm{~min}$

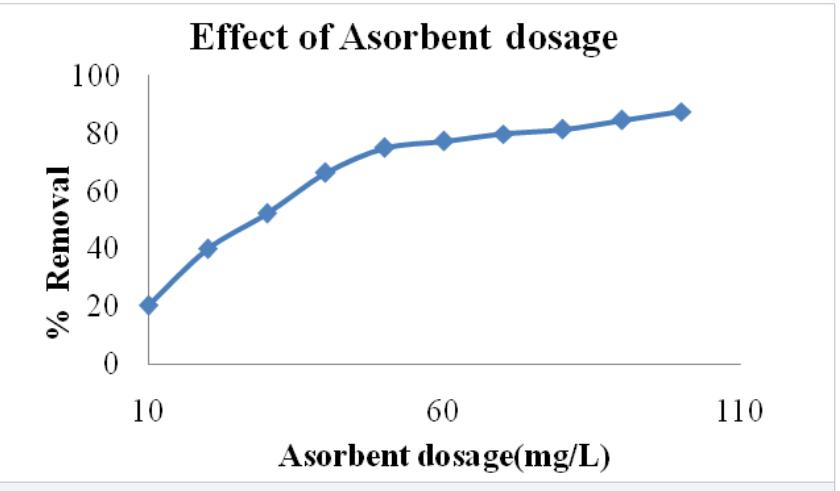

Figure 4: [RB]: 20 mg/ L; Contact time: 160min; pH: 6.

$$
\begin{aligned}
& \Delta \mathrm{G}^{\circ}=-\mathrm{RT} \ln \mathrm{k}_{\mathrm{d}} \\
& \ln \mathrm{k}_{\mathrm{d}}=\Delta \mathrm{S}^{\circ} / \mathrm{R}-\Delta \mathrm{H}^{\circ} / \mathrm{RT} \\
& \text { Where; }
\end{aligned}
$$

$\mathrm{k}_{\mathrm{d}}$ is the equilibrium constant, $\mathrm{C}_{\text {solid }}$ is the solid phase concentration at equilibrium (mg/ L), $\mathrm{C}_{\text {liquid }}$ is the liquid phase concentration at equilibrium $(\mathrm{mg} / \mathrm{L}), \mathrm{T}$ is the temperature in Kelvin and $\mathrm{R}$ is the gas constant. The Van't Hoff plot is drawn between $\ln k_{d}$ versus $1 / \mathrm{T}$.

The values of change in free energy $\left(\Delta G^{\circ}\right)$, enthalpy $\left(\Delta H^{\circ}\right)$ and entropy $\left(\Delta S^{\circ}\right)$ were calculated from the slopes and intercepts of the plot respectively.

\section{Results}

Results of effect of pH study were depicted as graph in figure 3. Color of the RB dye solution disappeared below the solution $\mathrm{pH}$ 4 even in the absence of adsorbent. Hence the $\mathrm{pH}$ dependence of $\mathrm{RB}$ dye adsorption onto TCZAC was studied in the $\mathrm{pH}$ range of 4 to 11 . The percentage removal increased as the $\mathrm{pH}$ of the solution increased in acidic medium up to 6. Afterwards the percentage removal found to decrease up to $\mathrm{pH} 11$. Maximum percentage removal was observed at $\mathrm{pH} 6$.

Percentage of removal of RB dye from aqueous solution with respect to different doses was shown in figure 4 . The percentage adsorption increased with the increase of the carbon dosage.

Result of the percentage of removal of RB dye from aqueous solution with respect to different contact time and with different initial concentration $(10,20,30,40$ and $50 \mathrm{mg} / \mathrm{L})$ was given Table 1 and shown in figure 5, and it is observed that the amount of solute adsorbed by the adsorbent, increased with the increase of initial concentrations of dye.

The results obtained from pseudo-first order and pseudosecond order kinetic models are presented in table 2 and concerned plots are shown in figure 6 and figure 7 correspondingly.

The results obtained from Intra particle diffusion model are presented in table 2 and concerned plots are shown in figure 8.

Figure 9 demonstrates the effect of temperature. That the percentage of removal of RB dye increased with, the increase of temperature from 303to $343 \mathrm{~K}$.

The results obtained from Langmuir model are presented in tables 3 and concerned isotherm plots are shown in figure 10. The dimensionless separation factor $\mathrm{R}_{\mathrm{L}}$ values calculated for various initial concentrations at different temperatures are given in table 4.

The results obtained from the Freundlich isotherm model are given in table 3. Representative isotherm plots are shown in figure 11 .

The results obtained from the Temkin isotherm model are recorded in Table 3 and concerned isotherm plots are shown in figure 12 . 
Table 1: Percentage of removal of dye and amount of dye adsorbed at 303K.

\begin{tabular}{|l|l|l|}
\hline $\begin{array}{l}\text { Initial } \\
\text { concentration } \\
\text { (mg/ L) }\end{array}$ & $\begin{array}{l}\text { Percentage of removal } \\
\text { of dye at equilibrium }\end{array}$ & $\begin{array}{l}\text { Amount of dye } \\
\text { adsorbed at } \\
\text { equilibrium (mg/g) }\end{array}$ \\
\hline 10 & 77.5 & 07.75 \\
\hline 20 & 75.0 & 15.00 \\
\hline 30 & 71.7 & 21.50 \\
\hline 40 & 68.8 & 27.50 \\
\hline 50 & 65.5 & 32.75 \\
\hline
\end{tabular}

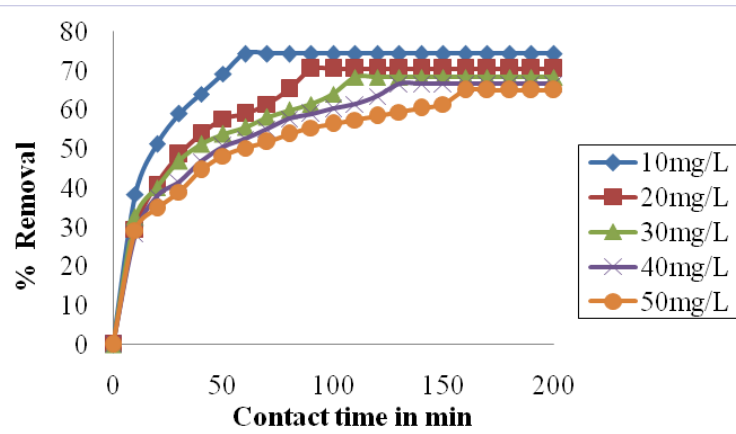

Figure 5: [RB]: 10-50 mg/ L; Dose: 50 mg/ L; pH: 6.

Table 2: Kinetic parameters for the removal of RB dye onto TCZAC. Initial dye concentration ( $\left.\mathrm{mg} \mathrm{L}^{-1}\right)$

\begin{tabular}{|l|c|c|c|c|c|}
\hline $\begin{array}{l}\text { Kinetic } \\
\text { parameters }\end{array}$ & $\mathbf{1 0}$ & $\mathbf{2 0}$ & $\mathbf{3 0}$ & $\mathbf{4 0}$ & $\mathbf{5 0}$ \\
\hline
\end{tabular}

Pseudo - first order constant

\begin{tabular}{|l|c|c|c|c|c|}
\hline $\mathrm{k}_{1}\left(\mathrm{~min}^{-1}\right)$ & 0.032 & 0.025 & 0.020 & 0.018 & 0.014 \\
\hline $\mathrm{q}_{\mathrm{e}^{\prime} \text { exp }}\left(\mathrm{mg} \mathrm{g}^{-1}\right)$ & 7.750 & 15.00 & 21.50 & 27.5 & 32.75 \\
\hline $\mathrm{q}_{\mathrm{e}_{\text {, cal }}}\left(\mathrm{mg} \mathrm{g}^{-1}\right)$ & 5.26 & 10.18 & 13.87 & 17.82 & 19.41 \\
\hline $\mathrm{R}^{2}$ & 0.996 & 0.994 & 0.987 & 0.994 & 0.997 \\
\hline $\mathrm{SSE}$ & & & $\mathbf{7 . 5 8}$ & & \\
\hline
\end{tabular}

\section{Pseudo-second-order constants}

\begin{tabular}{|l|c|c|c|c|c|}
\hline $\mathrm{k}_{2}\left(\mathrm{~g} \mathrm{mg}^{-1} \mathrm{~min}^{-1}\right)$ & 0.0130 & 0.0037 & 0.0020 & 0.0013 & 0.0012 \\
\hline $\mathrm{q}_{\mathrm{e}, \text { cal }}\left(\mathrm{mg} \mathrm{g} \mathrm{g}^{-1}\right)$ & 8.197 & 16.667 & 24.390 & 32.258 & 37.037 \\
\hline $\mathrm{h}\left(\mathrm{mg} / \mathrm{g} \mathrm{min}^{-}\right)$ & 0.876 & 1.037 & 1.220 & 1.307 & 1.597 \\
\hline $\mathrm{R}^{2}$ & 0.996 & 0.996 & 0.996 & 0.995 & 0.994 \\
\hline
\end{tabular}

\begin{tabular}{l|r|r} 
SSE & $\mathbf{2 . 8 3}$
\end{tabular}

Intra-particle diffusion constants

\begin{tabular}{|l|c|c|c|c|c|}
\hline $\mathrm{k}_{\mathrm{p}}\left(\mathrm{mg} \mathrm{g}^{-1} \mathrm{~min}^{-1}\right)$ & 0.63 & 0.94 & 1.10 & 2.04 & 2.19 \\
\hline $\mathrm{C}\left(\mathrm{mg} \mathrm{g}^{-1}\right)$ & 2.308 & 5.337 & 8.747 & 6.085 & 8.703 \\
\hline $\mathrm{R}^{2}$ & 0.998 & 0.998 & 0.997 & 0.999 & 0.998 \\
\hline
\end{tabular}

The constants obtained from Dubinin-Radushkevich isotherm are collected in table 3 and the concerned isotherm plots are shown in figure 13.

The results obtained from thermodynamics study are presented in table 5 and representative plots are shown in figure 14.

The effect of ionic strength is shown in the figure 15.

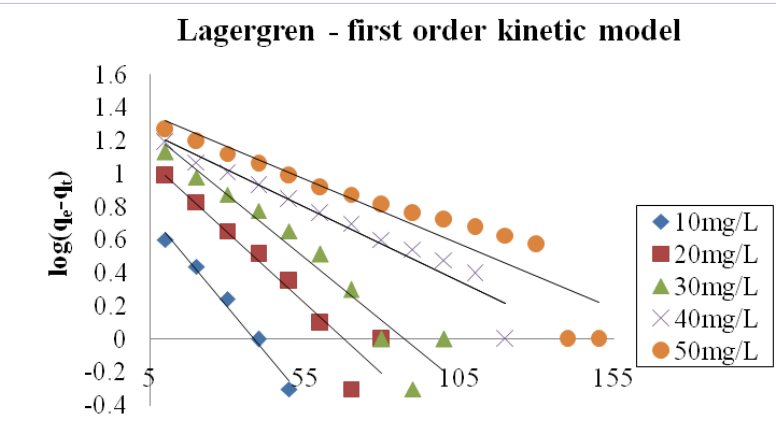

Time in min

Figure 6: [RB]: 10-50 mg/ L; Dose: 50 mg/ 50 mL; pH: 6.

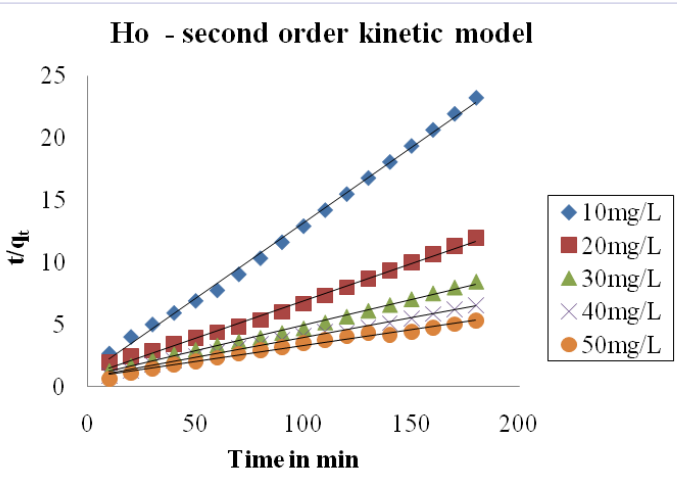

Figure 7: [RB]: 10-50 mg/ L; Dose: $50 \mathrm{mg} / 50 \mathrm{~mL}$; $\mathrm{pH}: 6$.

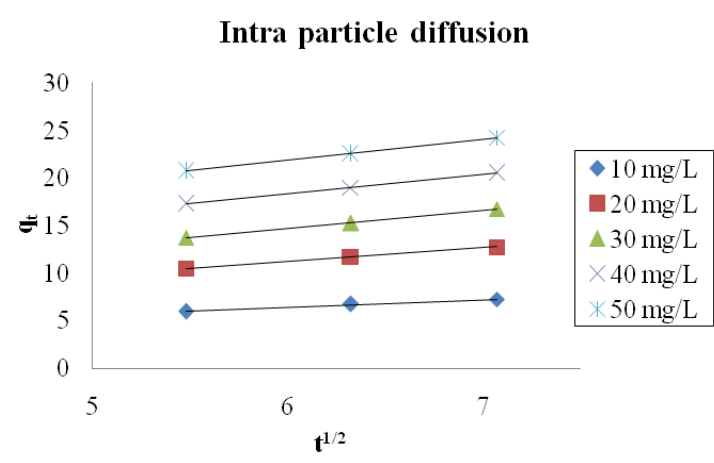

Figure 8: [RB]: 10-50 mg/ L; Dose: $50 \mathrm{mg} / 50 \mathrm{~mL}$; $\mathrm{pH}: 6$.

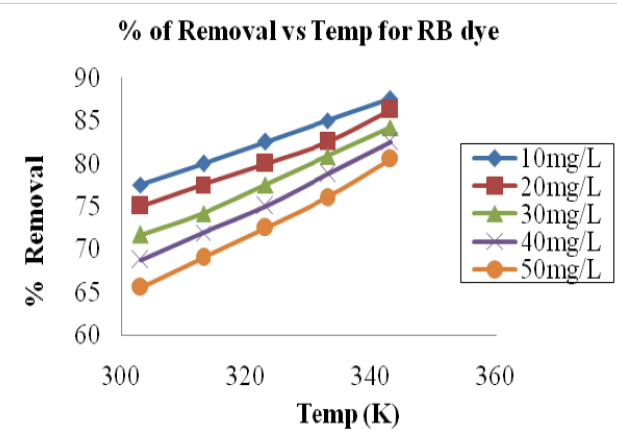

Figure 9: Adsorption isotherm of RB onto TCZAC at different temperature. [RB]: 10-50 mg/ L; Dose: $50 \mathrm{mg} / 50 \mathrm{~mL}$; Contact time: $160 \mathrm{~min}$ 


\section{Discussion}

\section{Effect of solution $\mathrm{pH}$}

Disappearance of color of the RB dye below the solution $\mathrm{pH} 4$ in the absence of adsorbent may be due to change in the structure of the RB dye as described in indicator theories. Trend in percentage of adsorption with respect to $\mathrm{pH}$ of the solution can be interpreted by; the point of zero charge $\left(\mathrm{pH}_{\mathrm{ZPC}}\right)$ of TCZAC and the speciation of the RB dye at different $\mathrm{pH}$ of the solution as below.

$\mathrm{pH}_{\mathrm{zpc}}$ of the adsorbent is 7.When the solution $\mathrm{pH}$ is below $\mathrm{pH}_{\mathrm{zpc}}$ that is 7,the surface of the adsorbent is positively charged [16].The lower percentage removal at lower $\mathrm{pH}$ infers that the dye might have acquired positive charge as reduced molecular ions $\left(\mathrm{CH}^{+}\right)$ and surface of the adsorbent would have rendered electrostatic repulsion towards dye cations. Increase of solution $\mathrm{pH}$ would decrease the positive charge on the adsorbent which explains

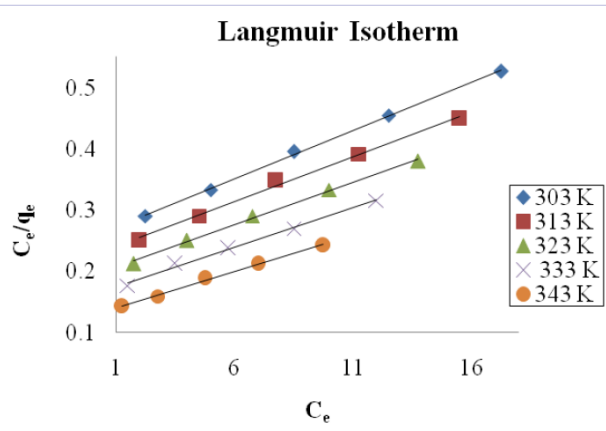

Figure 10: [RB]: 10-50 mg/ L; Dose: 50 mg/ 50 mL; Time: 160min.

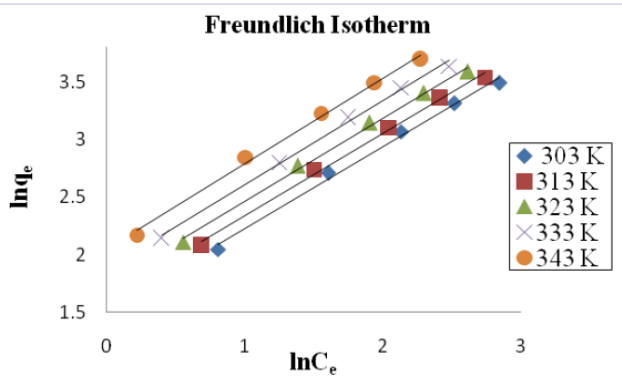

Figure 11: [RB]: 10-50 mg/ L; Dose: 50 mg/ 50 mL; Time: $160 \mathrm{~min}$.

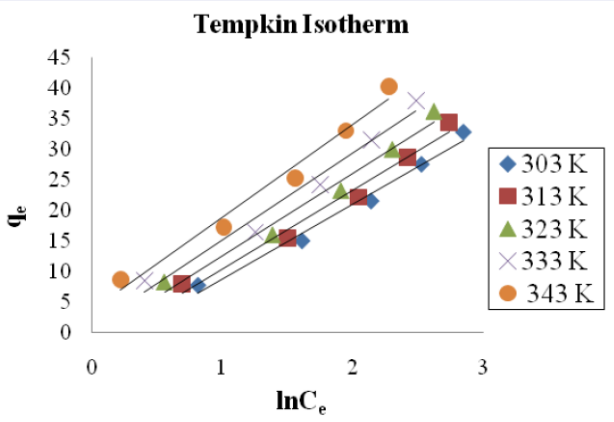

Figure 12: [RB]: 10-50 mg/ L; Dose: 50 mg/ 50 mL; Time: $160 \mathrm{~min}$.
Table 3: Isotherm parameters for removal of RB dye onto TCZAC.

\begin{tabular}{|c|c|c|c|c|c|}
\hline \multirow{2}{*}{ Isotherm model } & \multicolumn{5}{|c|}{ Temperature (K) } \\
\hline & 303 & 313 & 323 & 333 & 343 \\
\hline \multicolumn{6}{|c|}{ Langmuir constants } \\
\hline $\mathrm{q}_{\mathrm{m}}\left(\mathrm{mg} \mathrm{g}^{-1}\right)$ & 66.67 & 71.43 & 76.92 & 83.33 & 90.91 \\
\hline $\mathrm{b}\left(\mathrm{L} \mathrm{mg}^{-1}\right)$ & 0.059 & 0.062 & 0.067 & 0.075 & 0.086 \\
\hline $\mathrm{R}^{2}$ & 0.999 & 0.995 & 0.996 & 0.995 & 0.997 \\
\hline \multicolumn{6}{|c|}{ Freundlich constants } \\
\hline $\mathrm{k}_{\mathrm{f}}\left(\mathrm{mg} \mathrm{g}^{-1}\right)$ & 32.73 & 41.59 & 54.83 & 74.30 & 110.9 \\
\hline $\mathrm{n}$ & 1.410 & 1.399 & 1.389 & 1.372 & 1.348 \\
\hline $\mathrm{R}^{2}$ & 0.994 & 0.996 & 0.996 & 0.996 & 0.995 \\
\hline \multicolumn{6}{|c|}{ Temkin constants } \\
\hline $\mathrm{b}_{\mathrm{T}}(\mathrm{J} / \mathrm{mg})$ & 20.41 & 25.92 & 30.86 & 35.08 & 38.34 \\
\hline $\mathrm{a}_{\mathrm{T}}(\mathrm{L} / \mathrm{mg})$ & 0.758 & 0.833 & 0.9345 & 1.065 & 1.267 \\
\hline $\mathrm{R}^{2}$ & 0.983 & 0.977 & 0.976 & 0.975 & 0.976 \\
\hline \multicolumn{6}{|c|}{ Dubinin-Radushkevich constants } \\
\hline $\mathrm{q}_{\mathrm{D}}\left(\mathrm{mg} \mathrm{g}^{-1}\right)$ & 26.91 & 28.06 & 29.38 & 30.80 & 33.03 \\
\hline $\mathrm{E}\left(\mathrm{kJ} \mathrm{mol} \mathrm{m}^{-1}\right)$ & 0.500 & 0.707 & 0.745 & 0.845 & 1.000 \\
\hline $\mathrm{R}^{2}$ & 0.891 & 0.885 & 0.882 & 0.879 & 0.898 \\
\hline
\end{tabular}

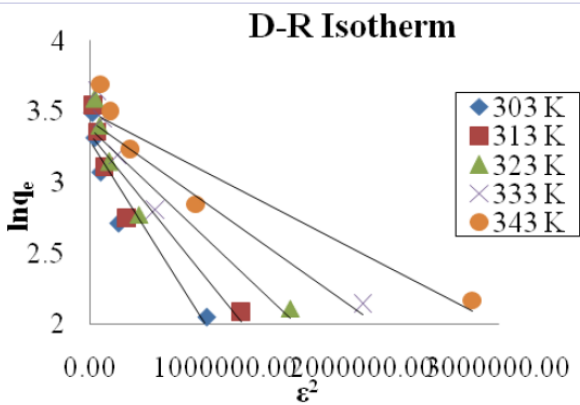

Figure 13: [RB]: 10-50 mg/ L; Dose: $50 \mathrm{mg} / 50 \mathrm{~mL}$; Time: $160 \mathrm{~min}$.

the increase of percentage removal of the dye up to $\mathrm{pH}$ 6. When the solution $\mathrm{pH}$ is above 6 , the surface of the adsorbent becomes slightly positively charged and the dye might have acquired negative charge which would be attracted by the adsorbent. This positive charge on the adsorbent would have decreased with the increase of $\mathrm{pH}$ and hence the attraction between the dye anion and the adsorbent would have decreased. The decrease of percentage removal of the dye in alkaline medium that is $\mathrm{pH}$ of the solution is above 7 is attributed to electrostatic repulsion between the dye anion and the negative charge on the surface of the adsorbent.

\section{Effect of adsorbent dosage}

The increase of percentage adsorption with the increase of carbon dosage is due to increased carbon surface area and the availability of more adsorption sites [17].

\section{Effect of contact time and initial concentration}

The adsorption process is characterized by a rapid up take 
Table 4: Dimensionless separation factor $\left(\mathrm{R}_{\mathrm{L}}\right)$ for adsorption of RB dye onto TCZAC.

\begin{tabular}{|c|c|c|c|c|c|}
\hline \multirow{2}{*}{$\mathbf{C}_{\mathbf{i}}$ for RB dye } & \multicolumn{3}{|c|}{ Temperature (K) } & $\mathbf{3 3 3}$ & $\mathbf{3 4 3}$ \\
\hline & $\mathbf{3 0 3}$ & $\mathbf{3 1 3}$ & $\mathbf{3 2 3}$ & 0.573 & 0.538 \\
\hline $\mathbf{1 0}$ & 0.146 & 0.617 & 0.596 & 0.402 & 0.368 \\
\hline $\mathbf{2 0}$ & 0.079 & 0.446 & 0.425 & 0.309 & 0.280 \\
\hline $\mathbf{3 0}$ & 0.054 & 0.349 & 0.330 & 0.251 & 0.225 \\
\hline $\mathbf{4 0}$ & 0.041 & 0.287 & 0.270 & 0.212 & 0.189 \\
\hline
\end{tabular}

Table 5: Thermodynamic parameters of rose Bengal by Terminalia catappa Linn.

\begin{tabular}{|c|c|c|c|c|c|c|c|}
\hline \multirow{2}{*}{$C_{i a}$ for RB dye } & \multicolumn{5}{|c|}{$\Delta G\left(\mathrm{~kJ} \mathrm{~mol}^{-1}\right)$} & \multirow{2}{*}{$\Delta \mathrm{H}\left(\mathrm{kJ} \mathrm{mol}^{-1}\right)$} & \multirow{2}{*}{$\Delta \mathrm{S}\left(\mathrm{Jk}^{-1} \mathrm{~mol}^{-1}\right)$} \\
\hline & $303 \mathrm{~K}$ & $313 \mathrm{~K}$ & $323 \mathrm{~K}$ & $333 \mathrm{~K}$ & $343 \mathrm{~K}$ & & \\
\hline 10 & -3.116 & -3.608 & -4.165 & -4.803 & -5.550 & 15.215 & 60.260 \\
\hline 20 & -2.768 & -3.219 & -3.724 & -4.294 & -5.237 & 15.364 & 59.487 \\
\hline 30 & -2.338 & -2.745 & -3.322 & -3.985 & -4.765 & 16.079 & 60.418 \\
\hline 40 & -1.987 & -2.442 & -2.951 & -3.627 & -4.423 & 16.304 & 60.044 \\
\hline 50 & -1.615 & -2.083 & -2.604 & -3.192 & -4.044 & 16.395 & 59.154 \\
\hline
\end{tabular}

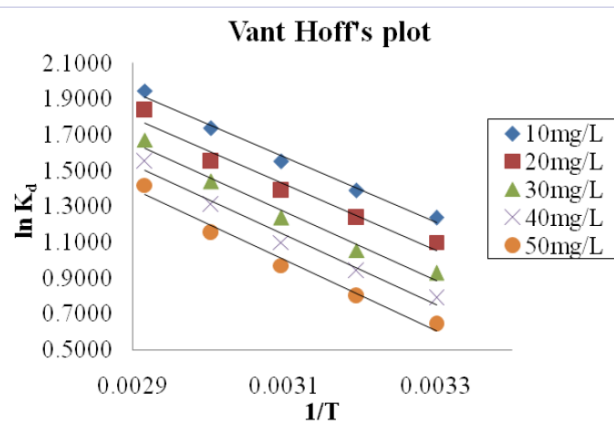

Figure 14: Plot of Inkd vs. 1/T for adsorption of RB onto TCZAC.

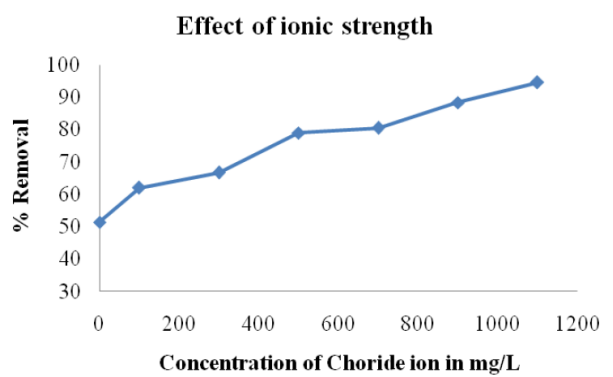

Figure 15: [RB]: $50 \mathrm{mg} / \mathrm{L}$; Dose: $50 \mathrm{mg} / 50 \mathrm{~mL}$; Contact time: $60 \mathrm{~min}$.

at initial stages. The percentage of removal increased with the increase of contact time. However, the time to attain equilibrium decreased with the increase of initial concentration of the dye solution. This is due to the decrease in the ratio of available adsorption sites to the concentration of solute in the solution with the increase of the initial concentration [18,19]. Increase of quantity adsorbed with the increase of initial concentration is due to higher driving force obtained because of concentration effect in the solution phase.

\section{Pseudo-first order and Pseudo-second order kinetic models}

From the result of kinetics study it is observed the initial sorption rate, ' $h$ ', increased from 0.8757 to 1.5974 with an increase of initial concentration of adsorbate from $10 \mathrm{mg} / \mathrm{L}$ to $50 \mathrm{mg} / \mathrm{L}$.

The regression coefficient $\left(\mathrm{R}^{2}\right)$ values were ranged from 0.987 to 0.997 and from 0.994 to 0.996 for the pseudo-first order and pseudo-second order kinetic models respectively. The best fitting kinetic model was determined by comparing the 'calculated adsorption capacity' $\left(\mathrm{q}_{\mathrm{e}(\mathrm{call})}\right)$ values from the respective kinetic models with the experimentally determined adsorption capacity $\left(\mathrm{q}_{\mathrm{e}(\exp )}\right)$ at equilibrium. The kinetic model which gives the closer ' $\mathrm{q}_{\mathrm{e}(\mathrm{cal)}}$ ' values with the experimental ' $\mathrm{q}_{\mathrm{e}(\exp )}$ ' values can be considered as the best fitting kinetic model. This can be known from the statistical tool 'Sum of Squared Error' (SSE).

$$
S S E=\sqrt{\sum^{\left[\left(q_{e}\right)_{\text {exp }}\left(q_{e}\right)_{c a l}\right]^{2} / N}}
$$

Where; $\mathrm{N}$ is the number of data points, $\left(\left(\mathrm{q}_{\mathrm{e}}\right)_{\exp }\right)$ is the experimental $\mathrm{q}_{\mathrm{e}}$ and $\left(\left(\mathrm{q}_{\mathrm{e}}\right)_{\text {cal }}\right)$ is the calculated $\mathrm{q}_{\mathrm{e}}$. The kinetic model which gives lowest SSE value is the best describing kinetic model.

Between the pseudo-first order and pseudo-second order, the pseudo second order kinetic model seems to best describe the adsorption of RB dye as the SSE value of pseudo-second order model is smaller than the pseudo-first order kinetic model.

\section{Intra-particle diffusion study}

The linear plots are attributed to the macro pore diffusion which is the accessible sites of adsorption. This is attributed to the instantaneous utilization of the most readily available adsorbing sites on the adsorbent surface. 
The $\mathrm{k}_{\mathrm{p}}$ values were found to increase from 0.63 to 2.19 with an increase of RB dye concentration which revealed that the rate of adsorption is governed by the diffusion of RB dye within the pores of the adsorbent.

\section{Effect of temperature}

The increase of percentage of removal with the increase of temperature is due to increased surface activity and increased in kinetic energy of the dye molecule. Since the \% of removal increased with the increase of temperature, the adsorption was endothermic nature.

\section{Langmuir isotherm}

The regression coefficient $\left(R^{2}\right)$ values are ranged from 0.995 to 0.997 for all the studied temperatures. These results show the best fitting of the equilibrium data with Langmuir isotherm. Further it is noticed that adsorption capacities were slightly increased with an increase of temperature.

These the $R_{L}$ values were lie in between 0 and 1 which indicates the favourable adsorption of RB dye onto TCZAC.

In general Langmuir constant values infer a better performance of TCZAC.

\section{Freundlich isotherm}

The regression coefficient $\left(\mathrm{R}^{2}\right)$ for Freundlich isotherms are ranged from 0.994 to 0.969 for all the studied temperatures viz. $303,313,323,333$ and $343 \mathrm{~K}$. It indicates that the experimental data fit well into the Freundlich isotherm models.

Further it is noticed that Freundlich constant the adsorption capacity $\mathrm{k}_{\mathrm{f}}(\mathrm{mg} / \mathrm{g})$ increased from32.734 to 110.917 with the increase of temperature.

The adsorption intensity ' $\mathrm{n}$ ' values are ranged from 1.347 to 1.4104 i.e., between 1 and 10, which indicate the favourable physical adsorption [20].

\section{Temkin isotherm}

The regression coefficient $\left(\mathrm{R}^{2}\right)$ values ranged from 0.975 to 0.983 and these results show the best fitting of the equilibrium data with Temkin isotherm. Equilibrium binding constant ' $\mathrm{a}_{\mathrm{T}}$ ' values $(\mathrm{L} / \mathrm{g})$ and the Temkin constant related to heat of sorption, $\mathrm{b}_{\mathrm{T}}$ values $(\mathrm{kJ} / \mathrm{mg})$ have low values and $\mathrm{B}$ value ranged from 0.002 to 0.001 . Hence the adsorption belongs to physisorption.

\section{Dubinin - Radushkevich isotherm}

The regression coefficient $\left(R^{2}\right)$ values are ranged from 0.879 to 0.898 for the five studied temperatures. The theoretical saturation capacity $\mathrm{q}_{\mathrm{D}}$ values $(\mathrm{mg} / \mathrm{g}$ ) found to increase from 26.907 to 33.029 with the increase of temperature.

Values of the mean free energy $\mathrm{E}(\mathrm{kJ} / \mathrm{mol})$ ranged from 0.5 to 1 .These very low values of ' $E$ ' support the physisorption interaction.

\section{Adsorption thermodynamics}

The negative values of $\Delta G^{\circ}$ show that the adsorption is spontaneous. The positive values of $\Delta \mathrm{H}^{\circ}$ show the endothermic nature of adsorption process. The $\Delta \mathrm{H}^{\circ}$ values were within the range of 1-93 kJ/ mol which confirms the physisorption [21,22]. The positive values of $\Delta S^{\circ}$ show the increased disorder and randomness at the solid solution interface. During adsorption some structural changes occur at the surface of the adsorbent. The adsorbed water molecules which are displaced by the adsorbate species, might have gained more translational entropy than is lost by the adsorbate molecules, thus allowing the prevalence of randomness in the system [23]. The enhancement of adsorption capacity of the activated carbon at higher temperatures was attributed to the enlargement of the size of the pore and the activation of the adsorbent surface.

\section{Effect of ionic strength}

Adsorption of Rose Bengal found to increase with an increase of $\mathrm{NaCl}$ concentration as shown in figure 15. This may be due to compression of the electrical double layer by the $\mathrm{Cl}^{-}$anion and also due to common ion effect of $\mathrm{Na}^{+}$ion which drive dye to the sorbent.

\section{Conclusion}

Zinc Chloride Activated (TCZAC) was prepared from fruit shells of Terminalia catappa Linn, found to have good capacity to absorb RB dye. Equilibrium of adsorption was achieved around 50 to 160 minutes for the dosage of $50 \mathrm{mg} / 50 \mathrm{~mL}$ of solution at room temperature of $303 \mathrm{~K}$ for the initial concentrations of RB dye solutions ranging from 10 to $50 \mathrm{mg} / \mathrm{L}$. Maximum removal ( $77.5 \%$ for the dye concentration of $10 \mathrm{mg} / \mathrm{L}$ at $303 \mathrm{~K}$ ) was recorded at $\mathrm{pH} 6$. The $\%$ of removal found to increase with the increase of temperature $(86.25 \%$ for the dye concentration of $10 \mathrm{mg} / \mathrm{L}$ at $303 \mathrm{~K}$ ). Kinetic of the adsorption process was found to follow the pseudo second order kinetic model. Adsorption capacity data obtained from the Langmuir, Freundlich, and Dubinin-Radushkevich isotherms indicated that TCZAC was effective in removing RB dye from aqueous solution. Further the adsorption energy values obtained from Dubinin-Radushkevich and Temkin isotherms supported physisorption mechanism. The separation factor $\mathrm{R}_{\mathrm{L}}$ values of Langmuir isotherm indicated that the adsorption was favourable. The thermodynamics parameters indicated that the adsorption process is endothermic and spontaneous and physisorption in nature.

\section{Declarations}

It is purely individual work and not having any association with academic bodies for financial support. Therefore conflict of interest is not applicable. No human subject was used for this study.

\section{References}

1. Namasivayam C, Radhika R, Suba S. Uptake of dyes by a promising locally available agricultural solid waste: coir pith. Waste Manag. 2001;21(4):381-7.

2. Inbaraj BS, Sulochana N. Mercury adsorption on a carbon sorbent derived from fruit shell of Terminalia catappa. J Hazard Mater. 2006;133(1-3):283-90. 
3. Ramesh K, Rajappa A, Nandhakumar V. Adsorption of Methylene Blue onto Microwave Assisted Zinc Chloride Activated carbon prepared from Delonix Regia pods- isotherm and Thermodynamic Studies. Research Journal of Chemical Sciences. 2014;4(7):36-42.

4. Lagergren S, Svenska BK. Zurtheorie der sogenannten adsorption geloesterstoffe. Vetenskapsakad. Handl. 1898;24:1-39.

5. Ho YS, McKay G. Pseudo-second order model for sorption processes. Process Biochemistry. 1999;34:451-465.

6. Walter J Weber, J Carrell Morris. Kinetics of Adsorption on Carbon from Solution. Journal of the Sanitary Engineering Division, ASCE. 1963;89(2):31-59.

7. Lin Y, HeX, Han G, Tian Q, Hu W. Removal of crystal violet from aqueous solution using powdered mycelial biomass of Ceriporia lacerata P2. J Environ Sci (China). 2011;23(12):2055-62.

8. Vijayakumar G, Tamilarasan R, Dharmendirakumar M. Adsorption, Kinetic, Equilibrium and Thermodynamic studies on the removal of basic dye Rhodamine-B from aqueous solution by the use of natural adsorbent perlite. J. Mater. Environ. Sci. 2012;3(1):157-170.

9. Azraa Achmad, Jain Kassim, Tong Kim Suan, Rozaini Che Amat, Tan Lean Seey. Equilibrium, Kinetic and Thermodynamic Studies on the Adsorption of Direct Dye onto a Novel Green Adsorbent Developed from Uncaria Gambir Extract. Journal of Physical Science. 2012;23(1):1-13.

10. Weber TW, Chakravorti RK. Pore and solid diffusion models for fixedbed adsorbers. AIChE J. 1974;20:228-238.

11. Kannan N, Sundaram MM. Kinetics and mechanism of removal of methylene blue by adsorption on various carbons- A comparative study. Dyes and Pigments. 2001;51(1):25-40.

12. Langmuir I. The adsorption of gases on plane surfaces of glass, mica and platinum. J Am Chem Soc. 1918;40(9):1361-1403.

13. Freundlich HMF. Over the adsorption in solution. The Journal of Physical Chemistry. 1906;57:385-471.
14. Aharoni C, Ungarish M. Kinetics of activated chemisorption Part 2-Theoretical models. J Chem Soc., Faraday Trans. 1. 1977;73:456464

15. Dubinin MM. The potential theory of adsorption of gases and vapors for adsorbents with energetically non-uniform surface. Chem Rev. 1960;60(2):235-241.

16. Nandhakumar V, Rajathi A, Ramesh K, Elavarasan A. Isotherm models for the adsorption of Crystal violet dye onto Zinc chloride activated carbon. Int J Nano Corr Sci and Engg. 2015;2(5):375-391.

17. Kannan N. A Study on Removal of Nickel by Adsorption on Fly ash Indian J Env Prot. 1991;11(7):514-518.

18. Abechi ES, Gimba CE, Uzairu A, Kagbu JA. Kinetics of adsorption of methylene blue onto activated carbon prepared from palm kernel shell. Archives of Applied Science Research.2011;3(1):154-164.

19. Garg VK, Gupta R, Bala Yadav A, Kumar R. Dye removal from aqueous solution by adsorption on treated sawdust. Bioresour Technol. 2003;89(2):121-4.

20. H Freundlich. Adsorption in Solutions. Journal of Physical Chemistry. 1906;57:384-410.

21. Arivoli S, Kalpana K, Sudha R, Rajachandrasekar T. Comparative Study on the Adsorption Kinetics and Thermodynamics of Metal Ions onto Acid Activated Low Cost Carbon. E-Journal of Chemistry. 2007;4(2):238-254

22. Gong R, Sun Y, Che J, Liu H, Yang C. Effect of Chemical Modification on Dye Adsorption Capacity of Peanut Hull. Dyes and Pigments. 2005;67(3):175-181.

23. Salam MA. Adsorption of nitroaniline onto high surface area nanographene. Journal of Industrial and Engineering Chemistry. 2015;28:67-72 